\title{
Perancangan Alat Pemanggang Menggunakan Pendekatan Antropometri
}

\author{
Azmi $^{1}$, Muhammad Arif ${ }^{2}$, Diki M Ramadani ${ }^{3}$ \\ 1,2,3Program Studi Teknik Industri, Sekolah Tinggi Teknologi Dumai \\ Jl. Utama Karya Bukit Batrem II \\ Emai: azmi.omy@gmail.com
}

\begin{abstract}
ABSTRAK
Alat pemanggang yang digunakan saat ini pada umumnya masih menggunakan kawat penjepit yang berbentuk persegi. Ikan atau ayam yang akan dipanggang disusun dan dijepit kemudian diletakkan diatas ruang bakar dan dilakukan pengipasan secara manual. Melalui cara ini didapati hasil pemanggangan yang tidak merata atau hangus pada bagian tertentu dikarenakan jarak ruang bakar terlalu dekat. Selain itu pengipasan secara manual juga membutuhkan tenaga khusus untuk jangka waktu yang lama.Penelitian ini merancang alat dengan pendekatan antropometri untuk mendapatkan dimensi ergonomis serta dilengkapi empat kipas dibawah yang dapat diatur jaraknya ke ruang bakar. Perancangan ini juga dilengkapi handle untuk membalikkan panggangan dan rak sebagai tempat meletakkan hasil panggangan. Alat ini memiliki Panjang $79 \mathrm{~cm}$, lebar $60 \mathrm{~cm}$ dan tinggi 93,2 cm. Adapun ukuran antropometri yang digunakan adalah dimensi tinggi siku, tinggi genggaman tangan (knuckle) pada posisi rileks kebawah dan diameter genggaman. Alat ini dibuat dengan biaya Rp 1.348.000, serta telah dilakukan pengujian dan diperoleh waktu pemanggangan yang lebih cepat dibandingkan cara manual.
\end{abstract}

Kata Kunci: Alat pemanggang, Antropometri, Perancangan

\begin{abstract}
Grill that are used today generally still use a square-shaped clamp wire. Fish or chicken to be grilled are arranged and clamped then placed on the combustion chamber and fanned manually. Through this method, it is found that the results of grilling are uneven or scorched in certain parts due to the distance of the combustion chamber being too close. In addition, manual fanning also requires special worker for a long period of time. This study designs a tool with an anthropometric approach to obtain ergonomic dimensions and is equipped with four fans below which can be adjusted to the distance to the combustion chamber. This design is also equipped with a handle to reverse the grill and a shelf as a place to put the grilled. This tool has a length of $79 \mathrm{~cm}$, a width of $60 \mathrm{~cm}$ and a height of $93.2 \mathrm{~cm}$. The anthropometric measurements used are the dimensions of the elbow height, the height of the hand grip (knuckle) in the relaxed downward position and the diameter of the grip. This tool was made at a cost of Rp. 1,348,000, and has been tested and the grilling time is faster than the old way.
\end{abstract}

Keywords: Grills, Anthropometry, Design 


\section{Pendahuluan}

Perancangan adalah suatu proses untuk menganalisis, menilai, memperbaiki dan menyusun suatu kerja, baik sistem fisik maupun non fisik yang optimal untuk waktu yang akan datang dengan berdasarkan informasi yang ada. Langkah-langkah dalam perancangan dimulai dari desain berupa sketsa gambar suatu produk, merencanakan bahan-bahan yang diperlukan dalam pembuatan produk, dilanjutkan dengan manufacturing (pembuatan) produk dan merencanakan biaya produksi untuk memperkirakan besar biaya yang akan dikeluarkan dalam pembuatan suatu produk.

Pemanggangan adalah salah satu proses memasak bahan makanan seperti ikan atau ayam dengan menggunakan panas api yang tinggi dan langsung berada dibawah bahan makanan yang sedang dipanggang. Alat yang digunakan disebut dengan pemanggang yang dilengkapi dengan jeruji kawat yang berfungsi sebagai penahan bahan makanan yang dipanggang. Proses pemanggangan pada umumnya dimulai dengan menyusun bahan makanan didalam alat pemanggang dan diletakkan diatas ruang bakar. Untuk mendapatkan hasil yang maksimal haruslah dilakukan pengipasan secara manual agar bahan makanan matang secara merata dan tidak terjadi kehangusan. Tentunya cara ini membutuhkan seorang pekerja yang secara terus menerus melakukan pengipasan dan membutuhkan waktu lama untuk menyelesaikan satu proses pemanggangan. Hal ini tentunya dinilai tidak efektif jika melakukan proses pemanggangan dalam jumlah yang besar, terutama proses pengipasan yang dapat menyebabkan kelelahan.

Penelitian ini dilakukan sebagai salah satu usaha untuk merancang alat pemanggang dengan pendekatan antropometri dengan menerapkan tiga dimensi antropometri kedalam perancangan alat agar nyaman digunakan.Selain itu perancangan ini dilengkapi dengan fitur yang dapat membantu dan meringankan pekerjaan pemanggangan. Perancangan ini mengubah proses pengipasan yang sebelumnya dilakukan secara manual dengan menggunakan kipas dibawah ruang bakar, adanya handle untuk membalikkan bahan makanan dengan cara memutar dan adanya rak sebagai tempat meletakkan bahan makanan yang akan dibakar.

Ergonomi atau ergonomics sebenarnya berasal dari bahasa Yunani yaitu Ergo yang berarti kerja dan Nomos yang berarti aturan atau hukum. Ergonomi mempunyai berbagai batasan arti, di Indonesia disepakati bahwa ergonomi adalah ilmu serta penerapannya yang berusaha untuk menyerasikan pekerjaan dan lingkungan terhadap orang atau sebaliknya dengan tujuan tercapainya produktifitas dan efisiensi yang setinggi-tingginya melalui pemanfaatan manusia seoptimaloptimalnya. Pendekatan khusus dalam disiplin ergonomi ialah aplikasi sistematis dari segala informasi yang releven yang berkaitan dengan karakteristik dan perilaku manusia dalam perancangan peralatan, fasilitas dan lingkungan kerja yang dipakai. Analisis dan penelitian ergonomi meliputi hal-hal yang berkaitan dengan anatomi (struktur), fisiologi, dan antropometri (ukuran) tubuh manusia. Data antropometri jelas diperlukan agar rancangan suatu produk bisa disesuaikan dengan orang yang akan mengoperasikan. Ukuran tubuh yang diperlukan pada hakikatnya tidak sulit diperoleh dari pengukuran secara individual.

Istilah antropometri biasanya digunakan oleh para ahli ergonomi dalam suatu sistem rancangan (design). Rancangan yang digunakan oleh manusia (design for use by people) meminta para perancang untuk memperhatikan ukuran tubuh manusia dalam pembentukan ruang lingkup dan produk-produk. Antropometri merupakan salah satu bagian yang menunjang Ergonomi, khususnya dalam perancangan suatu peralatan berdasarkan prinsip-prinsip ergonomi.Istilah Antropometri berasal dari kata "Anthropos" yang berarti manusia dan "Metricos" yang berarti ukuran. Secara definitive antropometri dinyatakan sebagai suatu yang 
menyangkut geometri fisik, massa, dan kekuatan tubuh. Sedangkan pengertian Antropometri adalah satu kumpulan dan numerik yang berhubungan dengan karakteristik fisik tubuh manusia, ukuran, bentuk dan kekuatan serta penerapan dari data tersebut untuk penanganan masalah desain. Penerapan anthropemetri ini akan dapat dilakukan jika tersedia nilai rata-rata (mean) dan standar deviasinya dari suatu distribusi normal. Adapun distribusi normal ditandai dengan adanya nilai rata-rata dan standar deviasi.

\section{Metode Penelitian}

Penelitian ini dilakukan di Workshop X yang beralamat di Jl. Jaya Indah, Kelurahan Jaya Mukti, Dumai Timur, Kota Dumai dengan objek dalam penelitian ini adalah Alat pemanggang. Data pada penelitian ini adalah data primer (utama) yang didapatkan dengan melakukan observasi dan wawancara tentang desain alat yang diinginkan berupa dimensi alat, features dan sistem kerja alat.Sedangkan data sekunder (pendukung) adalah data antropometri, literature dan penelitian terdahulu. Teknik pengumpulan data pada penelitian ini menggunakan pendekatan antropometri untuk menentukan beberapa dimensi dalam pembuatan alat.Data antropometri yang digunakan adalah data antropometri tangan manusia seperti terlihat pada tabel 1 dan 2.

Tabel 1.Antropometri telapak tangan orang Indonesia yang di dapat dari interpolasi data pheasant (1991) dan Suma'mur (1989) dan Nurmianto (1991).

\begin{tabular}{|c|c|c|c|c|c|c|c|c|c|}
\hline & \multirow[b]{2}{*}{ Dimensi Tubuh } & \multicolumn{4}{|c|}{ Pria } & \multicolumn{4}{|c|}{ Wanita } \\
\hline & & $5 \%$ & $\bar{X}$ & $95 \%$ & $\mathrm{SD}$ & $5 \%$ & $\bar{X}$ & $95 \%$ & $\mathrm{SD}$ \\
\hline 1 & Panjang tangan & 163 & 176 & 189 & 8 & 155 & 168 & 181 & 8 \\
\hline 2 & $\begin{array}{l}\text { Panjang telapak } \\
\text { tangan }\end{array}$ & 92 & 100 & 108 & 5 & 87 & 94 & 101 & 4 \\
\hline 3 & Panjang ibu jari & 45 & 48 & 51 & 2 & 42 & 45 & 48 & 2 \\
\hline 4 & Panjang telunjuk jari & 62 & 67 & 72 & 3 & 60 & 65 & 70 & 3 \\
\hline 5 & Panjang jari tengah & 70 & 77 & 84 & 4 & 69 & 74 & 79 & 3 \\
\hline 6 & Panjang jari manis & 62 & 67 & 72 & 3 & 59 & 64 & 69 & 3 \\
\hline 7 & Panjang jari klingking & 48 & 51 & 54 & 2 & 45 & 48 & 51 & 2 \\
\hline 8 & Lebar ibu jari & 19 & 21 & 23 & 1 & 16 & 18 & 20 & 1 \\
\hline 9 & Tebal ibu jari & 19 & 21 & 23 & 1 & 15 & 17 & 19 & 1 \\
\hline 10 & Lebar jari telunjuk & 18 & 20 & 22 & 1 & 15 & 17 & 19 & 1 \\
\hline 11 & Tebal jari telunjuk & 16 & 18 & 20 & 1 & 13 & 15 & 17 & 1 \\
\hline 12 & $\begin{array}{l}\text { Lebar telapak tangan } \\
\text { Metacarpal }\end{array}$ & 74 & 81 & 88 & 4 & 68 & 73 & 78 & 3 \\
\hline 13 & $\begin{array}{l}\text { Lebar telapak tangan } \\
\text { (sampai ibu jari) }\end{array}$ & 88 & 98 & 108 & 6 & 82 & 89 & 96 & 4 \\
\hline 14 & $\begin{array}{l}\text { Lebar telapak tangan } \\
\text { (minimum) }\end{array}$ & 68 & 75 & 82 & 4 & 64 & 59 & 74 & 3 \\
\hline 15 & $\begin{array}{l}\text { Tebal telapak tangan } \\
\text { (metacarpal) }\end{array}$ & 28 & 31 & 34 & 2 & 25 & 27 & 29 & 1 \\
\hline 16 & $\begin{array}{l}\text { Tebal telapak tangan } \\
\text { (sampai ibu jari) }\end{array}$ & 41 & 48 & 47 & 2 & 41 & 44 & 47 & 2 \\
\hline
\end{tabular}


Unitek : Jurnal Universal Teknologi

Vol. 14 No.1 Januari-Juni 2021

e-ISSN : 2580-2582, p-ISSN: 2089-3957

17 Diameter genggam (maksimum)

45

48

51

243

$\begin{array}{lll}46 & 49 & 2\end{array}$

18 Lebar maksimum (ibu jari ke jari kelingking)

177

192

206

$9 \quad 169$

$184 \quad 199 \quad 9$

19 Lebar fungsional maksimum (ibu jari ke jari lain)

3

123

20 Segi empat minimum yang dapat di lewati telapak tangan

$57 \quad 62$

67

51

56

61

Sumber: Nurmianto, 2004

Tabel 2. Data antropometri masyarakat Indonesia serta dimensionalnya

\begin{tabular}{|c|c|c|c|c|c|c|c|c|c|}
\hline \multirow{2}{*}{ No } & \multirow{2}{*}{ Dimensi Tubuh } & \multicolumn{8}{|c|}{ Persentil } \\
\hline & & $5 \%$ & $\mathrm{X}$ & $95 \%$ & SD & $5 \%$ & $\mathrm{X}$ & $95 \%$ & SD \\
\hline 1 & $\begin{array}{l}\text { Tinggi Tubuh } \\
\text { Berdiri Tegak }\end{array}$ & 1.532 & 1.632 & 1.732 & 61 & 1.464 & 1.563 & 1.662 & 60 \\
\hline 2 & Tinggi Mata & 1.425 & 1.520 & 1.615 & 58 & 1.350 & 1.446 & 1.542 & 58 \\
\hline 3 & Tinggi Bhu & 1.247 & 1.338 & 1.429 & 55 & 1.184 & 1.272 & 1.361 & 54 \\
\hline 4 & Tinggi Siku & 932 & 1.003 & 1.074 & 43 & 886 & 957 & 1.028 & 43 \\
\hline 5 & $\begin{array}{l}\text { Tinggi Genggaman } \\
\text { Tangan (knuckle) } \\
\text { pada posisi relaks } \\
\text { ke bawah }\end{array}$ & 655 & 718 & 782 & 39 & 646 & 708 & 771 & 38 \\
\hline 6 & $\begin{array}{l}\text { Tinggi Badan Pada } \\
\text { Posisi Duduk }\end{array}$ & 809 & 864 & 991 & 33 & 775 & 834 & 893 & 36 \\
\hline 7 & $\begin{array}{l}\text { Tinggi Mata posisi } \\
\text { Duduk }\end{array}$ & 694 & 749 & 804 & 33 & 666 & 721 & 776 & 33 \\
\hline 8 & $\begin{array}{l}\text { Tinggi Bahu posisi } \\
\text { Duduk }\end{array}$ & 523 & 572 & 621 & 30 & 501 & 550 & 599 & 30 \\
\hline 9 & $\begin{array}{l}\text { Tinggi Siku posisi } \\
\text { Duduk }\end{array}$ & 181 & 321 & 282 & 31 & 175 & 229 & 283 & 33 \\
\hline 10 & Tebal Paha & 117 & 140 & 263 & 14 & 115 & 140 & 165 & 15 \\
\hline 11 & $\begin{array}{l}\text { Jarak dari Pantat } \\
\text { ke Lutut }\end{array}$ & 500 & 545 & 590 & 27 & 488 & 537 & 586 & 30 \\
\hline 12 & $\begin{array}{l}\text { Jarak Lipat Lutut } \\
\text { ke Pantat }\end{array}$ & 405 & 450 & 495 & 27 & 488 & 537 & 586 & 30 \\
\hline 13 & Tinggi Lutut & 448 & 496 & 544 & 29 & 428 & 472 & 516 & 27 \\
\hline 14 & Tinggi Lipat Lutut & 361 & 403 & 445 & 26 & 337 & 382 & 428 & 28 \\
\hline 15 & Lebar Bahu & 382 & 424 & 446 & 26 & 342 & 385 & 428 & 26 \\
\hline 16 & Lebar Panggul & 291 & 330 & 371 & 24 & 298 & 345 & 392 & 29 \\
\hline 17 & Lebar Dada & 174 & 212 & 250 & 23 & 178 & 228 & 278 & 30 \\
\hline 18 & Lebar Perut & 174 & 228 & 282 & 33 & 175 & 231 & 287 & 34 \\
\hline 19 & $\begin{array}{l}\text { Jarak Siku ke } \\
\text { Ujung Jari }\end{array}$ & 405 & 439 & 473 & 21 & 374 & 409 & 287 & 34 \\
\hline 20 & Lebar Kepala & 140 & 150 & 160 & 6 & 135 & 146 & 157 & 7 \\
\hline 21 & Panjang Tangan & 161 & 176 & 191 & 9 & 153 & 168 & 183 & 9 \\
\hline 22 & Lebar Tangan & 71 & 79 & 87 & 5 & 64 & 71 & 78 & 4 \\
\hline 23 & $\begin{array}{l}\text { Jarak Bentang } \\
\text { dari Ujung jari } \\
\text { Tangan Kanan ke } \\
\text { Kiri }\end{array}$ & 1.792 & 1.923 & 2.051 & 87 & 1.4 & 1.523 & 1.646 & 75 \\
\hline 24 & $\begin{array}{l}\text { Tinggi Pegangan } \\
\text { Tangan (grip) pada } \\
\text { posisi Tanagn ke }\end{array}$ & 1.795 & 1.923 & 2.051 & 78 & 1.4 & 1.523 & 1.646 & 75 \\
\hline
\end{tabular}


Unitek : Jurnal Universal Teknologi

Vol. 14 No.1 Januari-Juni 2021

e-ISSN : 2580-2582, p-ISSN: 2089-3957

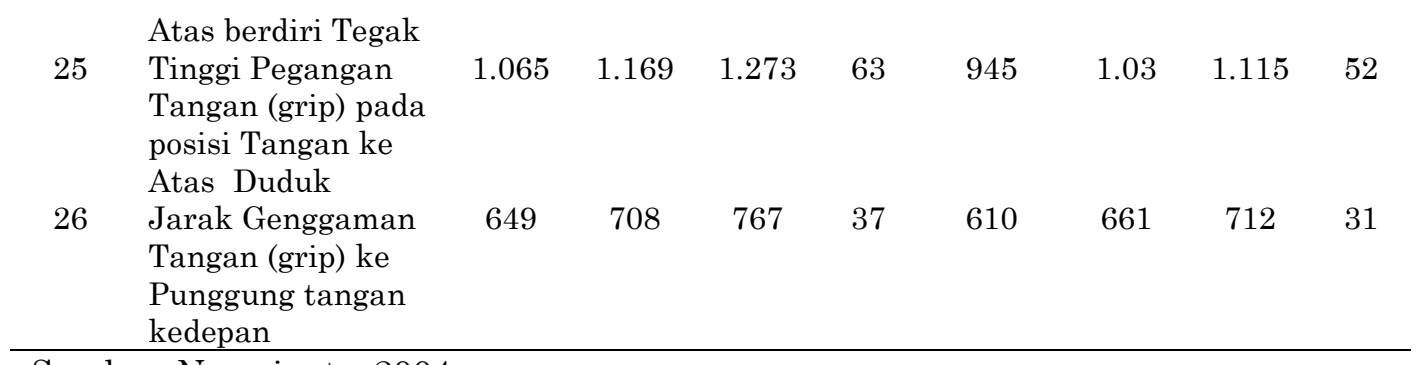

Sumber: Nurmianto, 2004

\section{Hasil dan Pembahasan}

Penelitian ini menggunakan pendekatan data antropometri satatis, dengan mengambil beberapa dimensi-dimensi yang menjadi bagian dasar untuk menentukan ukuran perancangan alat pemanggang.Adapun data Antropometri yang digunakan dalam penelitian ini adalah 3 dimensi yang dapat dilihat pada tabel 3 .

Tabel 3. Data antropometri dalam perancangan alat pemanggang

\begin{tabular}{rlrrr}
\hline No & Dimensi tubuh & Dimensi ke- & $\begin{array}{l}\text { Ukuran } \\
(\mathrm{mm})\end{array}$ & Persentil \\
\hline 1. & Tinggi siku & 4 & 932 & $5 \%$ \\
2. & Tinggi genggaman tanggan (knuckle) & 5 & 655 & $5 \%$ \\
$\quad$ pada posisi relaks ke bawah & & & \\
3. Diameter genggaman & 17 & 48 & $50 \%$ \\
\hline
\end{tabular}

Sumber: Nurmianto, 2004.

Tabel 3 adalah data-data antropometri yang digunakan dalam pembuatan alat pemanggang.Kemudian data antropometri diterjemahkan kedalam ukuran pembuatan alat yang terlihat pada tabel 4 .

Tabel 4. Penerapan data antropometri pada perancangan alat pemanggang

\begin{tabular}{|c|c|c|c|c|}
\hline No & Dimensi tubuh & $\begin{array}{l}\text { Ukuran } \\
(\mathrm{mm})\end{array}$ & Dimensi mesin & $\begin{array}{l}\text { Ukuran } \\
(\mathrm{mm})\end{array}$ \\
\hline & Tinggi siku & 932 & $\begin{array}{l}\text { Tinggi Kedudukan rak } \\
\text { pemanggang }\end{array}$ & 932 \\
\hline & $\begin{array}{l}\text { Tinggi genggaman } \\
\text { tanggan (knuckle) pada } \\
\text { posisi relaks ke bawah }\end{array}$ & 655 & Tinggi meja & 655 \\
\hline 3. & Diameter genggaman & 48 & $\begin{array}{l}\text { Ukuran pegangan rak } \\
\text { pemanggang }\end{array}$ & 48 \\
\hline
\end{tabular}

Sumber: Penelitian 


\section{Rancangan alat pemanggang}

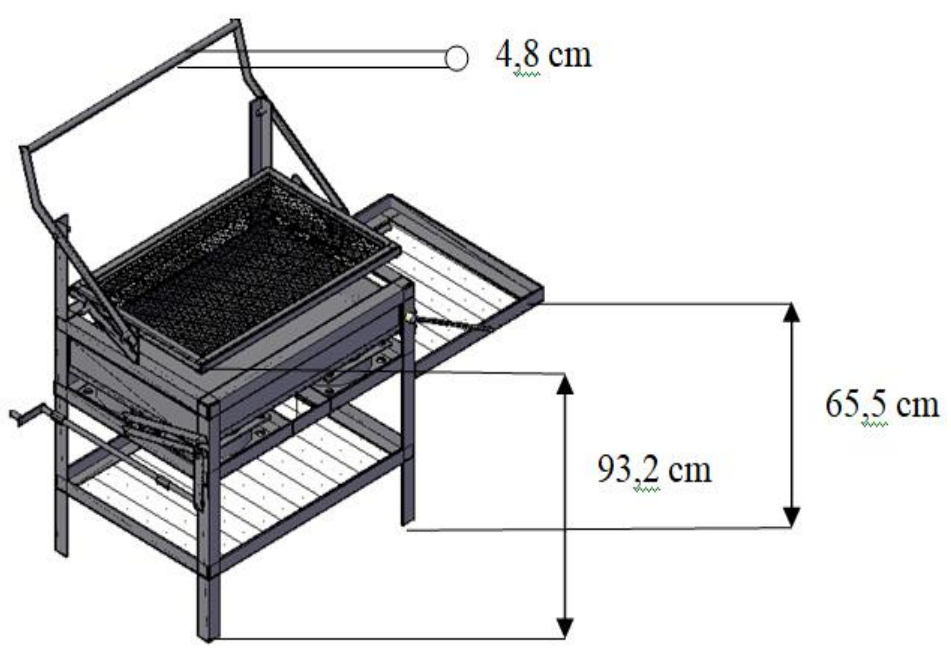

Gambar 1. Ukuran antropometri pada perancangan alat pemanggang

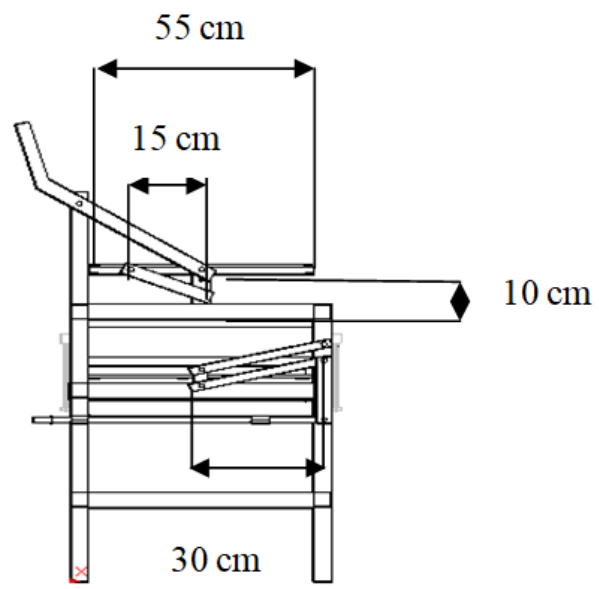

Gambar 2. Tampak samping kiri

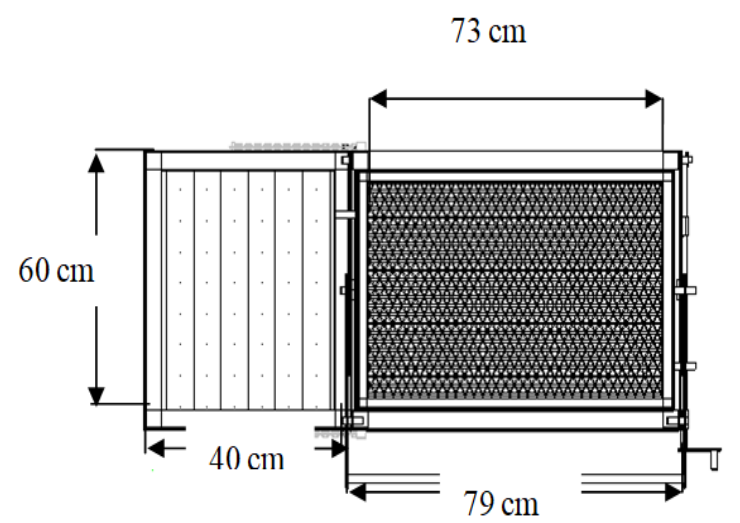

Gambar 4. Tampak atas

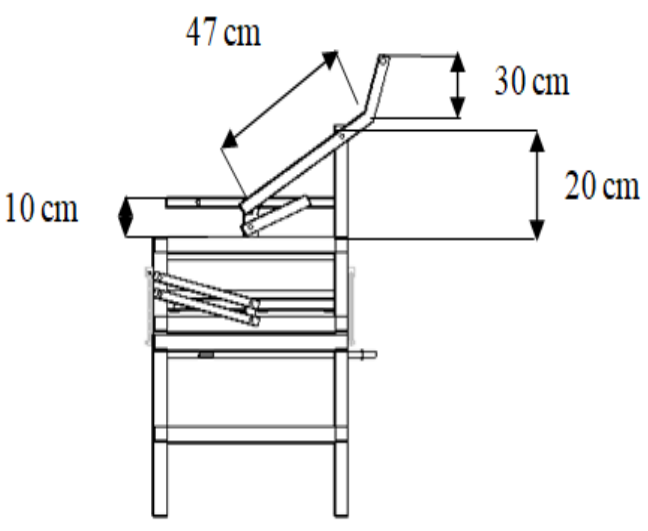

Gambar 3. Tampak samping kanan

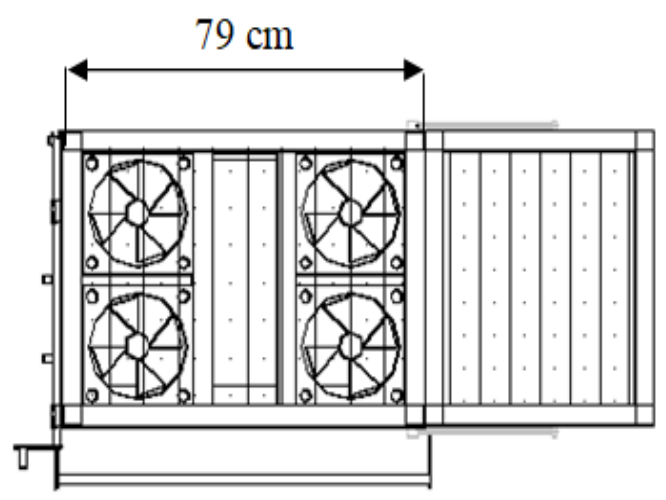

Gambar 5. Tampak bawah 


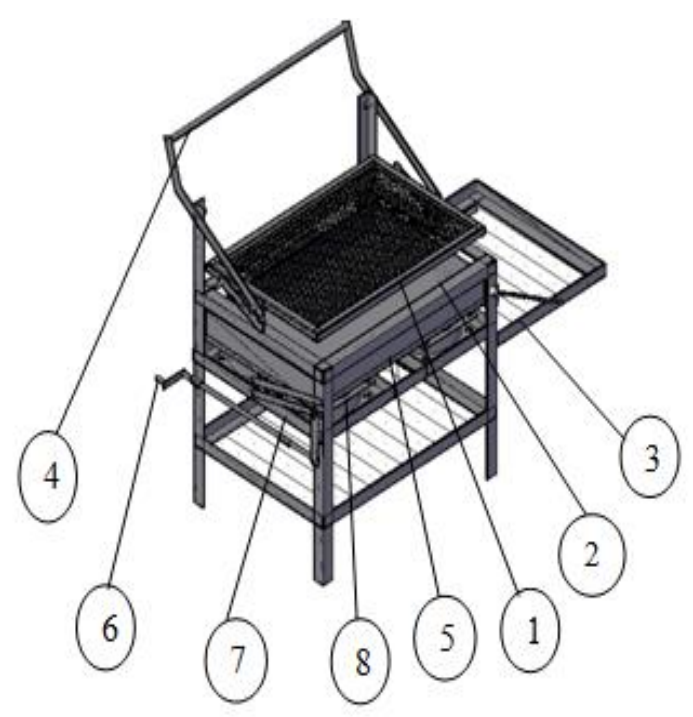

\section{Keterangan Gambar}

1. Rak pemanggang

2. Kerangka

3. Meja

4. Handlerak panggangan

5.Kerangka ruang bakar

6. Penyetel ruang bakar

7. Dudukan Kipas

8. Kipas

Gambar 6. Tampak isometri

\section{Hasil Rancangan Alat Pemanggang}

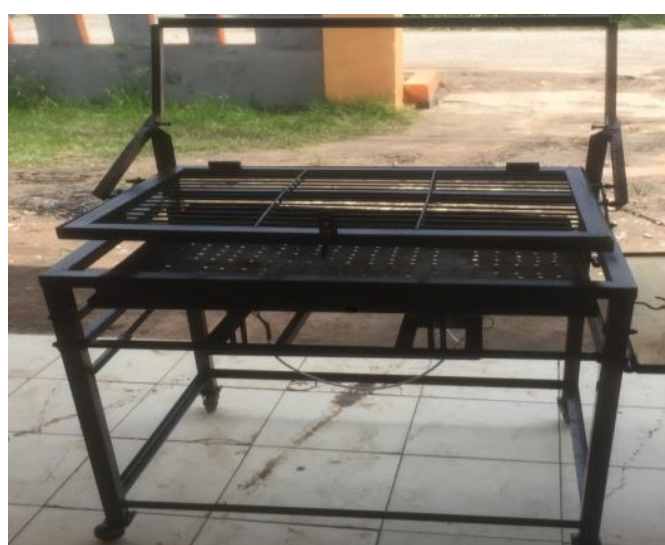

Gambar 7.Hasil perancangan

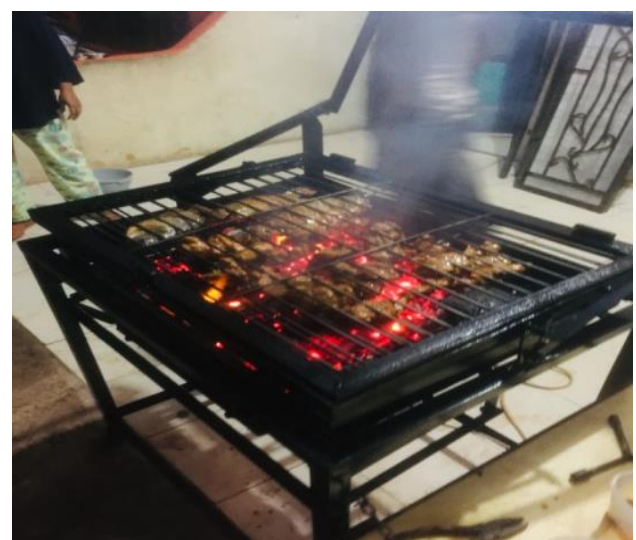

Gambar 8. Pengujian alat

\section{Pengujian Alat}

Pengujian alat dilakukan untuk mengetahui kinerja alat pemanggang dan mendapatkan perbandingan waktu pemanggangan dengan menggunakan pemanggang biasa dan pemanggang hasil rancangan. Adapun bahan makanan yang dipanggang adalah ayam dan ikan nila seperti terlihat pada tabel 5 dan 6 .

Tabel 5. Perbandingan waktu pada pemanggangan ayam

\begin{tabular}{ccccc}
\hline No & $\begin{array}{c}\text { Pemanggangan } \\
\text { ke- }\end{array}$ & $\begin{array}{c}\text { Jumlah ayam } \\
\text { (potong) }\end{array}$ & $\begin{array}{c}\text { Waktu Pemanggangan (menit) } \\
\text { Pemanggang biasa }\end{array}$ & $\begin{array}{c}\text { Pemanggang hasil } \\
\text { rancangan }\end{array}$ \\
\hline 1 & 1 & 8 & 19 & 11 \\
2 & 2 & 8 & 22 & 13 \\
3 & 3 & 8 & 25 & 14 \\
4 & 4 & 8 & 24 & 13
\end{tabular}


Unitek : Jurnal Universal Teknologi

Vol. 14 No.1 Januari-Juni 2021

e-ISSN : 2580-2582, p-ISSN: 2089-3957

Rata-rata waktu pemanggangan

22,5

12,75

Tabel 6. Perbandingan waktu pada pemanggangan ikan nila

\begin{tabular}{ccccc}
\hline No & $\begin{array}{c}\text { Pemanggangan } \\
\text { ke- }\end{array}$ & $\begin{array}{c}\text { Jumlah ikan nila } \\
\text { (ekor) }\end{array}$ & Pemanggang biasa & $\begin{array}{c}\text { Waktu Pemangangan (menit) } \\
\text { Pemangang hasil } \\
\text { rancangan }\end{array}$ \\
\hline 1 & 1 & 9 & 19 & 14 \\
2 & 2 & 9 & 22 & 15 \\
3 & 3 & 9 & 20 & 14 \\
Rata-rata waktu pemanggangan & & 20,3 & 14,3 \\
\hline
\end{tabular}

Sumber: penelitian

Dari hasil pengujian yang dilakukan terlihat bahwa waktu pemanggangan menggunakan alat rancangan lebih cepat dibandingkan menggunakan pemanggang biasa. Pada pemanggangan ayam yang dilakukan sebanyak 4 kali percobaan dengan masing-masing percobaan sebanyak 8 potong ayam diperoleh waktu rata-rata 12,75 menit menggunakan alat pemanggang hasil rancangan sedangkan menggunakan pemanggang biasa membutuhkan waktu 22,5 menit. Sedangkan pada pemanggangan ikan nila yang dilakukan sebanyak 3 kali percobaan dengan masingmasing percobaan 9 ekor diperoleh waktu 13,6 menit, lebih cepat 6 menit jika dibandingkan dengan menggunakan pemanggang biasa.

\section{Simpulan}

Alat pemanggang yang dirancang memiliki panjang $79 \mathrm{~cm}$, lebar $60 \mathrm{~cm}$ dan tinggi $93,2 \mathrm{~cm}$ yang dapat mengakomodasi penggunanya. Perancangan ini menggunakan pendekatan antropometri untuk 3 dimensi yang diterapkan pada alat diantaranya dimensi siku sebagai tinggi kedudukan rak pemanggang yaitu 93,2 cm, dimensi tinggi genggaman tangan (knuckle) pada posisi relaks kebawah sebagai tinggi meja yaitu $65,5 \mathrm{~cm}$ dan dimensi diameter genggaman sebagai ukuran pegangan (handle) rak pemanggang yaitu $4,8 \mathrm{~cm}$. Alat ini dilengkapi dengan featuretambahan untuk memudahkan penggunanya yaitu empat buah kipas yang berada dibawah ruang bakar yang dapat diatur jaraknya, handleuntuk membalikkan panggangan dan rak untuk meletakkan bahan makanan yang akan dipanggang maupun hasil panggangan. Alat ini dibuat dengan biaya Rp 1.348.000, serta telah dilakukan pengujian pada dua jenis bahan makanan dan diperoleh waktu pemanggangan yang lebih cepat dibanding pemanggangan dengan cara manual.

\section{Daftar Pustaka}

Azmi, A. (2020). Perancangan alat pencuci ubi kayu dengan pendekatan antropometri. Universal Teknologi, 13(2), 1-10.

Ginting, R. (2009). Perancangan Produk. Yogyakarta: Graha Ilmu.

Irawan, A., Lanya, B., \& Haryanto, B,. (2016). Uji kerja tungku paganngan performance test of the furnece grills. Jurnal Teknik Pertanian Lampung, $5(2), 73-80$.

Kastiawan, I.M., Ahmad, R, \& Salamun, K,.(2019). Rancang bangun oven untuk produksi sale pisang dari tungku tradisional. Mekanika-Jurnal Teknik Mesin, $5(1), 25-30$.

Noviriani, J.D.,\& Adianto, E.R..(2017). Alternatif rancangan alat panggang kue balok 
Unitek : Jurnal Universal Teknologi

Vol. 14 No.1 Januari-Juni 2021

e-ISSN : 2580-2582, p-ISSN: 2089-3957

ramah lingkungan liquefied petroleum gas (LPG). Jurnal Rekayasa Hijau, 1(3), 196-207.

Nurmantio, E. (2004). Ergonomi konsep dasar dan aplikasinya (Edisi kedua). Jakarta: Guna Widya.

Sasongko, R.J., \& Rivai, M,. (2018). Mesin pemanggang biji kopi dengan suhu terkendali menggunakan arduino due. Jurnal Teknik ITS, 7(2), 239-244.

Sutalaksana, I. (2012). Peta Proses Operasi (Operation Process Chart). Jakarta: Guna Widya.

Wignjosoebroto, S. (2006). Aplikasi distribusi normal dalam penetapan data antropometri. Jakarta: Guna widya. 